\title{
Titration of Parameters in Shared Ventilation With a Portable Ventilator
}

\author{
Sakina H Sojar, Austin M Quinn, William H Bortcosh, Paul C Decerbo, Esther Chung, \\ Carolyn J La Vita, and Gregory D Jay
}

\begin{abstract}
BACKGROUND: Dual-patient, single-ventilator protocols (ie, protocols to ventilate 2 patients with a single conventional ventilator) may be required in times of crisis. This study demonstrates a means to titrate peak inspiratory pressure (PIP), PEEP, and $\mathrm{F}_{\mathrm{IO}_{2}}$ for test lungs ventilated via a dual-patient, single-ventilator circuit. METHODS: This prospective observational study was conducted using a ventilator connected to 2 test lungs. Changes in PIP, PEEP, and $\mathrm{F}_{\mathrm{IO}_{2}}$ were made to the experimental lung, while no changes were made to the control lung. Measurements were obtained simultaneously from each test lung. PIP was titrated using 3D-printed resistors added to the inspiratory circuit. PEEP was titrated using expiratory circuit tubing with an attached manual PEEP valve. $\mathrm{F}_{\mathrm{IO}_{2}}$ was titrated by using a splitter added to the ventilator tubing. RESULTS: PIP, PEEP, and $\mathrm{F}_{\mathrm{IO}_{2}}$ were reliably and incrementally titratable in the experimental lung, with some notable but manageable changes in pressure and $\mathrm{F}_{\mathrm{IO}_{2}}$ documented in the control lung during these titrations. Similar results were measured in lungs with identical and different compliances. CONCLUSIONS: Pressures and $\mathrm{F}_{\mathrm{IO}_{2}}$ can be reliably adjusted when utilizing a dualpatient, single-ventilator circuit with simple, low-cost modifications to the circuit. This innovation could potentially be lifesaving in a resource-limited or crisis setting. Understanding the interactions of these circuits is imperative for making their use safer. Key words: mechanical ventilators; pandemics; critical care; three-dimensional printing; positive-pressure respiration; hospital equipment and supplies. [Respir Care 2021;66(5):758-768. (C) 2021 Daedalus Enterprises]
\end{abstract}

\section{Introduction}

The COVID-19 pandemic created a critical ventilator shortage emphasizing a need for utilizing dual-patient, single-ventilator protocols, which are procedures to ventilate 2 patients connected to a single conventional ventilator in a crisis setting when resources are limited (eg, mass casualty, disaster, pandemic). ${ }^{1-4}$ In 2020, regions of the United States approached this crisis setting. On March 26, 2020, Governor

Dr Sojar is affiliated with the Division of Pediatric Emergency Medicine, Department of Emergency Medicine, Alpert Medical School, Brown University, Rhode Island Hospital, Providence, Rhode Island. Drs Quinn and Jay are affiliated with the Department of Emergency Medicine, Alpert Medical School, Brown University, Rhode Island Hospital, Providence, Rhode Island. Dr Bortcosh is affiliated with the Division of Pediatric Critical Care Medicine, University of Florida Shands Hospital, Gainesville, Florida. Mr Decerbo and Dr Jay are affiliated with the Lifespan Simulation Center, Rhode Island Hospital, Providence, Rhode Island. Ms Chung and Ms La Vita are affiliated with the Division of Respiratory Therapy, Massachusetts General Hospital, Boston, Massachusetts. Dr Jay is affiliated with the School of Engineering, Brown University, Providence, Rhode Island.
Cuomo of New York announced that hospitals would be given permission to place 2 patients on a single ventilator because the medical system had been overwhelmed by the number of critically ill patients with COVID-19 who required mechanical ventilation. ${ }^{5,6}$ While some hospitals had developed dual-patient, single-ventilator protocols in the past, the establishment of these circuits has not been widely studied or disseminated. ${ }^{7}$

Dual-patient, single-ventilator protocols are an off-label usage of a traditional ventilator and have several limitations. ${ }^{8}$ One of the primary limitations is that ventilator settings for individual patients cannot be adjusted easily because both patients are exposed to the same ventilator settings. Patients

The authors have disclosed no conflicts of interest.

Correspondence: Sakina H Sojar MD, Department of Pediatric Emergency Medicine, Brown University, Hasbro Children's Hospital, 55 Claverick St, Office 243, Providence, RI 02903. E-mail:

sakina_sojar@brown.edu.

DOI: $10.4187 /$ respcare.08446 
infrequently require identical ventilation settings given differences in size, acid/base disturbances, and lung compliances. Furthermore, to avoid ventilator asynchrony, patients should receive neuromuscular blockade. Given this variability, a single change in ventilator settings could be beneficial to one patient but detrimental to another in the current shared ventilator model. ${ }^{7}$

This study adds to the literature by demonstrating how to adjust peak inspiratory pressure (PIP), PEEP, and $\mathrm{F}_{\mathrm{IO}_{2}}$ independently for each patient when utilizing a dualpatient, single-ventilator protocol. Titration of individual PIP has been described in recent literature, but titration of PEEP and $\mathrm{F}_{\mathrm{IO}_{2}}$ has not been discussed. ${ }^{9}$ Furthermore, we evaluated a dual-patient, single-ventilator protocol using an LTV 1200 ventilator (Vyaire Medical, Yorba Linda, California), which is a standard-issue ventilator from the U.S. government's Strategic National Stockpile in association with the American Association for Respiratory Care. This may allow others to more easily expand on this model if the need arises.

We hypothesized that PIP, PEEP, and $\mathrm{F}_{\mathrm{IO}_{2}}$ could be individually titrated when using a shared ventilator circuit. First, we aimed to demonstrate that PIP could be individualized by modifying one patient's inspiratory circuit with an in-line resistor, decreasing pressures distal to its insertion. Second, we sought to show that PEEP could be individualized by the addition of a manual PEEP valve and a one-way valve into one patient's expiratory circuit. Third, we aimed to demonstrate that $\mathrm{F}_{\mathrm{IO}_{2}}$ could be adjusted with additional oxygen flow with a one-way valve to an individual patient circuit. Lastly, we aimed to document any unexpected changes in delivered pressures or tidal volumes to either circuit as the adjustments were made. This paper will discuss these low-cost modifications to the dual-patient, single-ventilator protocol to individualize the ventilation of each patient while optimizing safety.

\section{Methods}

\section{Shared Ventilator Circuit Components}

The individualized, dual-patient, single-ventilator circuit, shown in Figure 1, was designed using an LTV 1200 ventilator, a splitter for the ventilator outlet port (A), a 3D-printed Y-piece for the exhalation valve line port (D), a 3D-printed oxygen tubing adapter (C), 3Dprinted resistors of various diameters (B), a one-way valve $(\mathrm{H})$, corrugated tubing, 2 manual manometers from 2 flow-inflating resuscitator bags (E), 2 endotracheal tube connectors, 2 sets of expiratory tubing for the LTV 1200 circuit (F), and 1 set of expiratory tubing for an LTV 900 circuit (G).

\section{QUICK LOOK}

\section{Current knowledge}

Preclinical data, clinical data, and case reports in both animal and human models support the feasibility of shared ventilation during times of ventilator shortages. The COVID-19 pandemic created a critical ventilator shortage in some areas of the United States, underscoring the need for further research shared ventilation. Although shared ventilation has been described previously, titration of individual settings when using these protocols has not been widely discussed in the literature.

\section{What this paper contributes to our knowledge}

Shared ventilation with a portable ventilator was accomplished using two exhalation valves, one with a manual PEEP valve. Resistors were used to control inspiratory flow and tidal volume to one test lung. Variable $\mathrm{F}_{\mathrm{IO}_{2}}$ was achieved by bleeding oxygen flow to one limb of the circuit. These modifications allowed successful shared ventilation of a lung model. Shared ventilation is a technique of last resort and safety of the system requires further testing.

\section{Experimental Setup and Apparatus}

The dual-patient, single-ventilator circuit was connected to Vent Aid training and test lungs (Michigan Instruments, Grand Rapids, Michigan). PIP, PEEP, and tidal volumes were measured using NICO2 respiratory profile monitors (Phillips Respironics, Murrysville, Pennsylvania) simultaneously for each test lung. Lung compliance was adjusted by using the dials provided on the training and test lungs and measured using the NICO2 monitors. $\mathrm{F}_{\mathrm{IO}_{2}}$ was measured with an in-line oxygen analyzer $\left(\mathrm{MaxO}_{2} \mathrm{ME}\right.$, Max Tec, Salt Lake City, Utah). A photograph of the experimental setup is shown in Figure 2.

\section{Equipment for PIP, PEEP, and $\mathrm{F}_{\mathrm{IO}_{2}}$ Titrations}

To titrate individual PIPs, a set of 3D-printed orifice plate resistors were manufactured. The orifice diameters of these inserts ranged from $2 \mathrm{~mm}$ to $7 \mathrm{~mm}$ in increments of $1 \mathrm{~mm}$. To titrate individual PEEPs, LTV 900 expiratory circuit tubing with the attached manual PEEP valve was added. To titrate individual $\mathrm{F}_{\mathrm{IO}_{2}}$, a splitter was 3D-printed to add supplemental oxygen into the circuit. 


\section{Shared Ventilation With a Portable Ventilator}

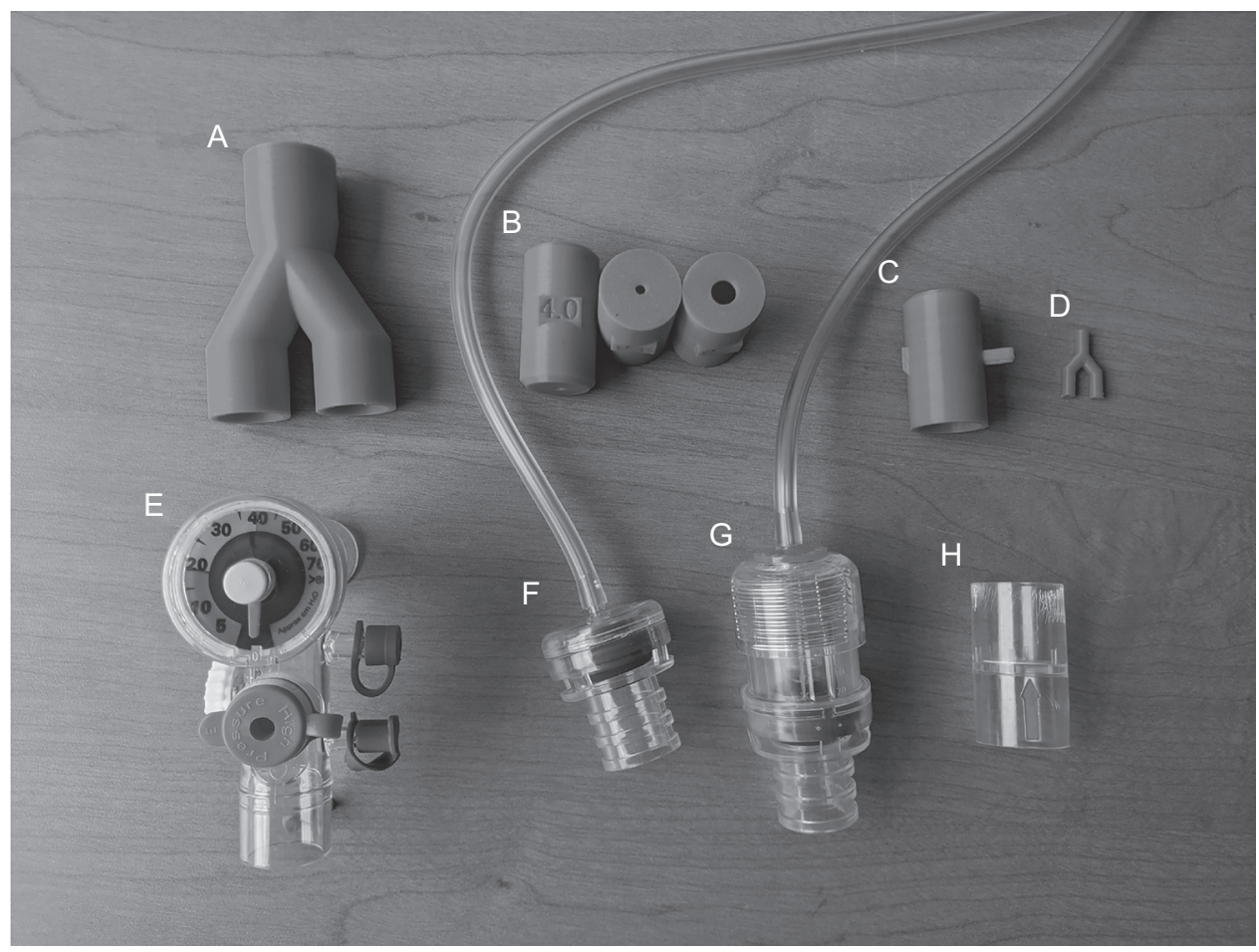

Fig. 1. Ventilator circuit components. A: Splitter for ventilator outlet port. B: 3D-printed resistors of various diameters. C: 3D-printed oxygen tubing adapter. D: 3D-printed Y-piece for exhalation valve line port. E: Manual manometer. F: LTV 1200 expiratory tubing. G: LTV 900 expiratory tubing. H: One-way valve.

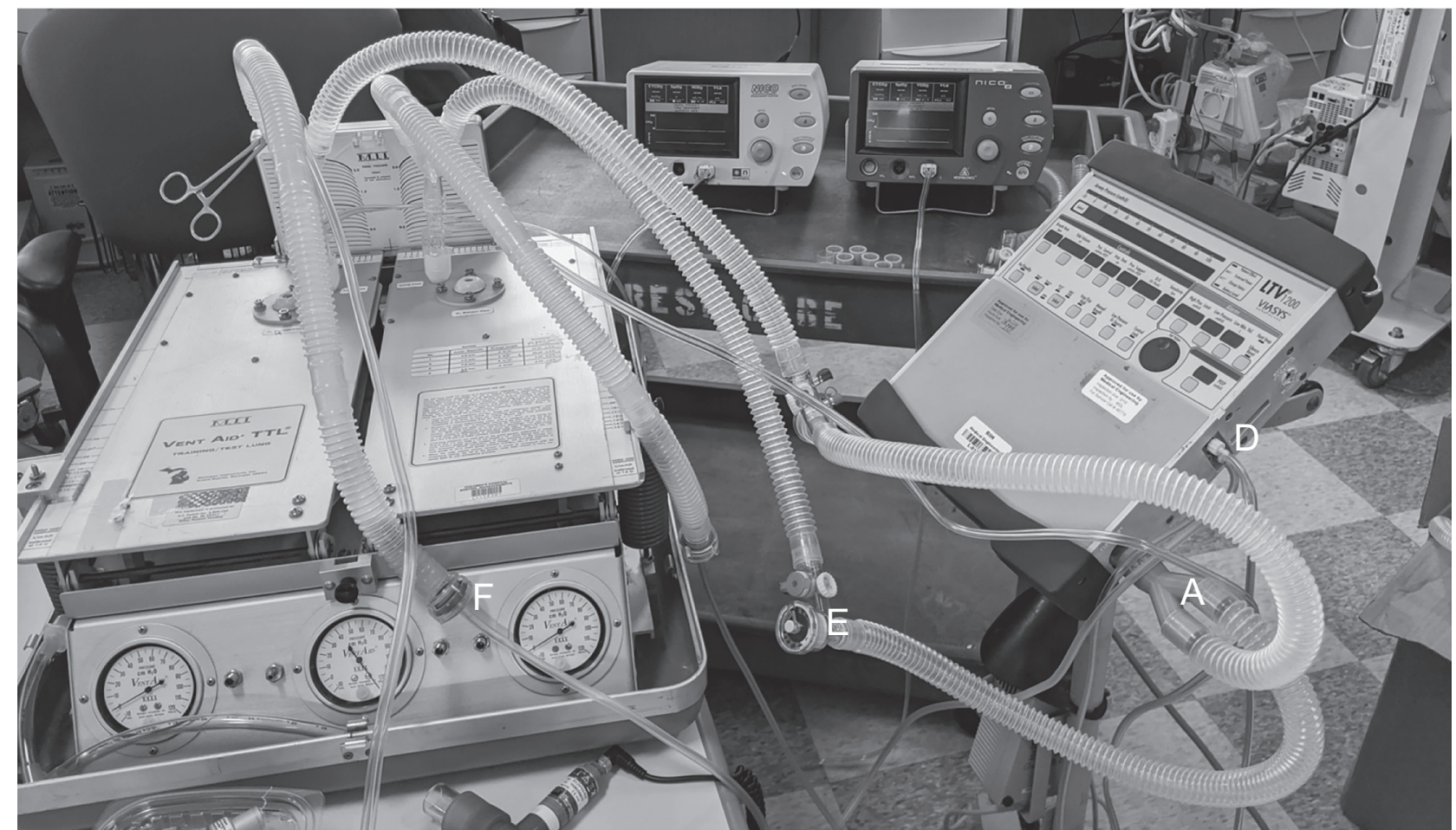

Fig. 2. Experimental set up (initial uniform circuit). A: Splitter for ventilator outlet port. D: 3D-printed Y-piece for exhalation valve line port. E: Manual manometer. F: LTV 1200 expiratory tubing. 


\section{Shared Ventilation With a Portable Ventilator}

All pieces were designed in Fusion 360 (Autodesk, San Rafael, California) using an outer diameter of $22 \mathrm{~mm}$ for the ventilator output, an inner diameter of $22 \mathrm{~mm}$ for corrugated tubing, and an inner diameter of $4 \mathrm{~mm}$ for oxygen tubing and expiratory valve lines. The parts were printed with poly (D,L-lactic acid) (PLA) polymer filament (Fillamentum, Hulín, Czech Republic) on a Prusa i3 MK3S (Prusa Research, Prague, Czech Republic), with print settings of $0.2 \mathrm{~mm}$ layer height, $100 \%$ infill, and default Fillamentum PLA nozzle and bed temperatures. No postprocessing was performed.

\section{Initial Uniform Circuit}

The ventilator was first connected to 2 test lungs. A 3Dprinted ventilation output splitter was inserted into the breathing circuit outlet port. A 3D-printed Y-piece was inserted into the exhalation valve drive line port. Corrugated tubing of equal lengths was attached to each limb of the inspiratory splitter of the breathing circuit, which connected to the test lungs. Two manual manometers were placed inline proximal to the insertion of the corrugated tubing into the test lungs. These manometers served a dual purpose. First, they allowed a safety feature consisting of a pop-off valve to temporize critically high pressures should they develop in the circuit. Second, they offered a second source of pressure monitoring. The flow transducer tubing from the control lung was connected to the flow transducer's highpressure sensing port and the flow transducer's low-pressure sensing port of the ventilator. The flow transducer tubing for the experimental lung was clamped so that no air would escape into the environment. Identical NICO2 sensors were placed in the most proximal point in the test lungs. The LTV 1200 expiratory circuits were connected to the ventilator with the expiratory Y-piece (Fig. 3A).

\section{Experiment Phases and Measurements}

All experimental trials were performed in pressure control mode. Delivered PIP, PEEP, and $\mathrm{F}_{\mathrm{IO}_{2}}$ settings were entered in the ventilator. Four trials were performed for each PIP, PEEP, and $\mathrm{F}_{\mathrm{IO}_{2}}$ titration. Each trial was done with either identical compliance $\left(0.06 \mathrm{~L} / \mathrm{cm} \mathrm{H}_{2} \mathrm{O}\right)$ or differential compliance $\left(0.03 \mathrm{~L} / \mathrm{cm} \mathrm{H}_{2} \mathrm{O}\right.$ and $\left.0.06 \mathrm{~L} / \mathrm{cm} \mathrm{H}_{2} \mathrm{O}\right)$ and with the ventilator settings set to either higher pressure settings (PIP 27 $\mathrm{cm} / \mathrm{H}_{2} \mathrm{O}$, PEEP $7 \mathrm{~cm} / \mathrm{H}_{2} \mathrm{O}, \mathrm{F}_{\mathrm{IO}_{2}} 0.21$, breathing frequency 12 breaths/min) or lower pressure settings (PIP $20 \mathrm{~cm} / \mathrm{H}_{2} \mathrm{O}$, PEEP $5 \mathrm{~cm} / \mathrm{H}_{2} \mathrm{O}, \mathrm{F}_{\mathrm{IO}_{2}} 0.21$, breathing frequency 12 breaths/min). The inspiratory to expiratory ratio was $1: 4$, making inspiratory time $1 \mathrm{~s}$ and expiratory time $4 \mathrm{~s}$. The pressure and volumes were continuously measured during each trial. Three separate tidal volumes were recorded for each adjustment of PIP, PEEP, or $\mathrm{F}_{\mathrm{IO}_{2}}$. When PIP, PEEP, or $\mathrm{F}_{\mathrm{IO}_{2}}$ was modified, a minimum of 2 min was allowed for the ventilator and NICO2 monitors to equilibrate prior to recording the findings.

\section{Titrating PIP}

Each resistor from $2 \mathrm{~mm}$ to $7 \mathrm{~mm}$ was sequentially added to the inspiratory circuit of the experimental lung proximal to the insertion of the manual manometer. Ventilator parameters were measured with each titration (Fig. 3B).

\section{Titrating PEEP}

A one-way valve was inserted into the inspiratory circuit of the experimental lung. The LTV 1200 expiratory port for the experimental lung was exchanged for LTV 900 expiratory tubing, as it contained an external manual PEEP valve. The control lung remained connected to the LTV 1200 expiratory port. The manual spring was then adjusted for the experimental lung to give additional PEEP beyond that which was being provided by the ventilator. Ventilator parameters were measured with each PEEP adjustment (Fig. 3C).

\section{Titrating $\mathrm{F}_{\mathrm{IO}_{2}}$}

A one-way valve was inserted into the inspiratory circuit of the experimental lung. A splitter with a connection for oxygen tubing was inserted in the inspiratory circuit of the experimental lung. Using an in-line oxygen analyzer, oxygen concentrations were measured in both test lungs. The experimental lung received supplemental oxygen flow though the splitter in addition to oxygen delivered from the ventilator. The control lung did not receive supplemental oxygen. Ventilator parameters were measured with each $\mathrm{F}_{\mathrm{IO}_{2}}$ titration (Fig. 3D).

\section{Statistical Analysis}

Descriptive statistics were used to describe the changes in tidal volume due to changes to inspiratory circuit resistance (Table 1), pre-set PEEP valves (Table 2), and oxygen flow (Table 3). The mean and 95\% CI of 3 measured tidal volume measurements were reported. The statistical modal value was used to report stably observed PIP, PEEP, and $\mathrm{F}_{\mathrm{IO}_{2}}$. No a priori statistical comparisons were planned or performed in this investigation. Descriptive statistical analyses were performed using Microsoft Office Excel 2010 (Microsoft, Redmond, Washington).

\section{Results}

PIP was reliably and incrementally titrated with the addition of sequential 3D-printed resistors to the inspiratory circuit. Evaluating PIP with test lungs set at identical compliance and higher pressure settings, the PIP delivered 


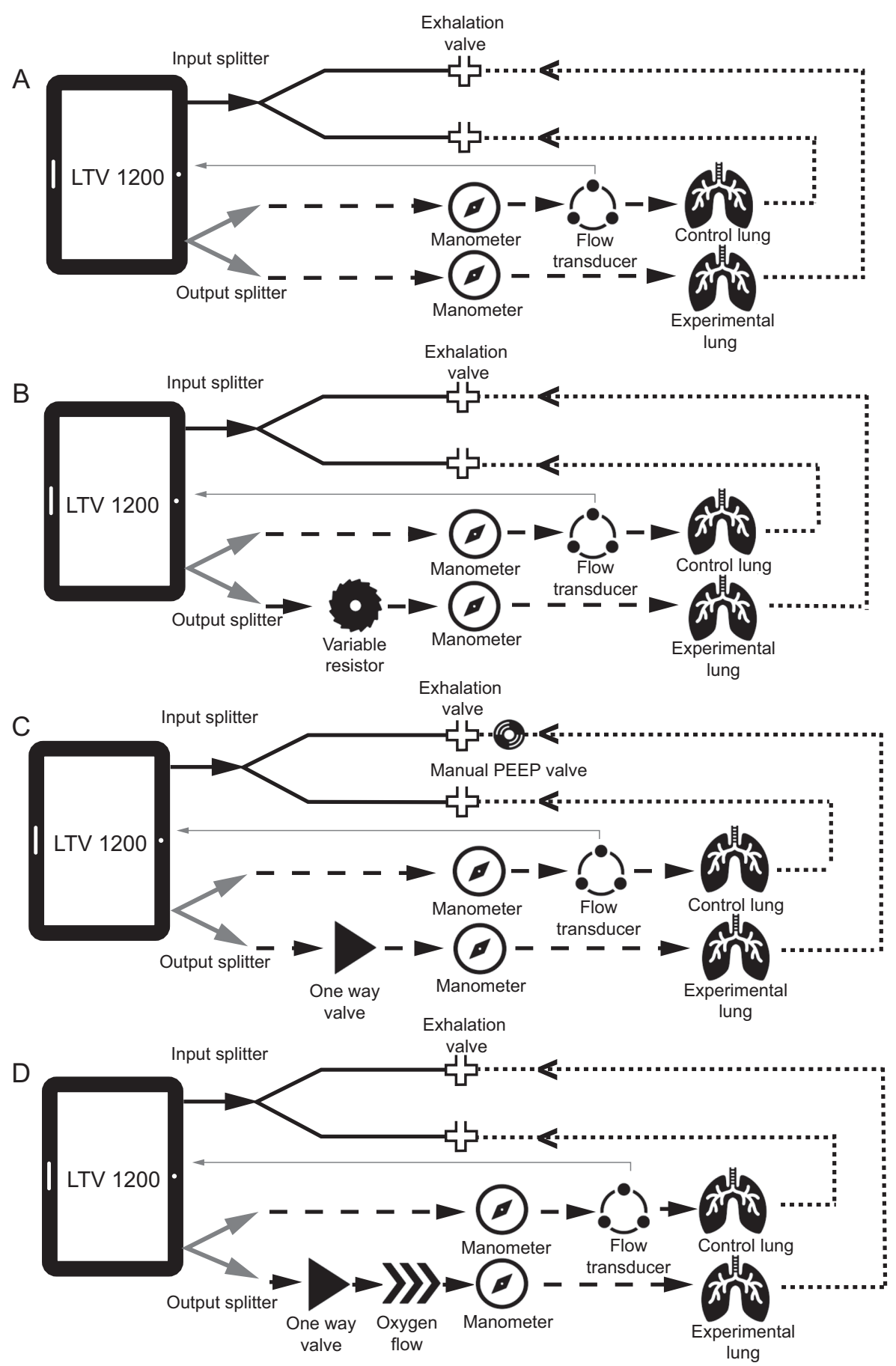

Fig. 3. Circuit diagrams for titration of each parameter. A: Initial uniform circuit. B: Titrating peak pressures. C: Titrating PEEP. D: Titrating $\mathrm{F}_{\mathrm{IO}_{2}}$.

to the experimental lung was adjustable from 10 to $24 \mathrm{~cm}$ $\mathrm{H}_{2} \mathrm{O}$. With identical compliance and lower pressure settings, the PIP delivered to the experimental lung was adjustable from 8 to $18 \mathrm{~cm} \mathrm{H}_{2} \mathrm{O}$. With differential compliance and higher pressure settings, the PIP delivered to the experimental lung was adjustable from 10 to $23 \mathrm{~cm} \mathrm{H}_{2} \mathrm{O}$. With differential compliance and lower pressure settings, the PIP delivered to the experimental lung was adjustable from 8 to $18 \mathrm{~cm} \mathrm{H}_{2} \mathrm{O}$ (Table 1).

It should be noted that the addition of a resistor to the inspiratory circuit of the experimental lung slightly increased the PIP delivery to the control lung. For example, with a 2 $\mathrm{mm}$ resistor in the "higher ventilator pressures" trial with identical test-lung compliance, the measured PIP delivered 
Table 1. Titration of PIP Using Varying Resistors

\begin{tabular}{|c|c|c|c|c|c|c|}
\hline & \multicolumn{3}{|c|}{ Control Lung } & \multicolumn{3}{|c|}{ Experimental Lung } \\
\hline \multicolumn{7}{|c|}{ Identical test-lung compliance with higher ventilator pressures } \\
\hline Compliance, $\mathrm{L} / \mathrm{cm} \mathrm{H}_{2} \mathrm{O}$ & \multicolumn{3}{|c|}{0.062} & \multicolumn{3}{|c|}{0.062} \\
\hline Resistor size, mm & $\begin{array}{c}\text { PIP, cm } \\
\mathrm{H}_{2} \mathrm{O}\end{array}$ & $\begin{array}{c}\text { PEEP, } \mathrm{cm} \\
\mathrm{H}_{2} \mathrm{O}\end{array}$ & $\begin{array}{l}\text { Mean } \mathrm{V}_{\mathrm{T}} \\
(95 \% \mathrm{CI}), \mathrm{L}\end{array}$ & $\begin{array}{c}\text { PIP, } \mathrm{cm} \\
\mathrm{H}_{2} \mathrm{O}\end{array}$ & $\begin{array}{c}\text { PEEP, } \mathrm{cm} \\
\mathrm{H}_{2} \mathrm{O}\end{array}$ & $\begin{array}{l}\text { Mean } \mathrm{V}_{\mathrm{T}} \\
(95 \% \mathrm{CI}), \mathrm{L}\end{array}$ \\
\hline 2 & 28 & 7 & $1.165(1.161-1.169)$ & 10 & 7 & $0.093(0.079-0.107)$ \\
\hline 3 & 27 & 7 & $1.154(1.150-1.158)$ & 13 & 7 & $0.318(0.311-0.326)$ \\
\hline 4 & 26 & 7 & $1.148(1.128-1.169)$ & 16 & 7 & $0.470(0.464-0.476)$ \\
\hline 5 & 26 & 7 & $1.124(1.124-1.125)$ & 18 & 7 & $0.593(0.588-0.598)$ \\
\hline 6 & 26 & 7 & $1.101(1.086-1.115)$ & 20 & 7 & $0.708(0.706-0.710)$ \\
\hline 7 & 25 & 7 & $1.068(1.066-1.070)$ & 21 & 7 & $0.832(0.828-0.836)$ \\
\hline None & 24 & 7 & $0.993(0.990-0.996)$ & 24 & 7 & $0.989(0.984-0.994)$ \\
\hline \multicolumn{7}{|c|}{ Identical test-lung compliance with lower ventilator pressures } \\
\hline Compliance, $\mathrm{L} / \mathrm{cm} \mathrm{H}_{2} \mathrm{O}$ & \multicolumn{3}{|c|}{0.059} & \multicolumn{3}{|c|}{0.059} \\
\hline Resistor size, mm & $\begin{array}{c}\mathrm{PIP}, \mathrm{cm} \\
\mathrm{H}_{2} \mathrm{O}\end{array}$ & $\begin{array}{c}\text { PEEP, } \mathrm{cm} \\
\mathrm{H}_{2} \mathrm{O}\end{array}$ & $\begin{array}{l}\text { Mean } \mathrm{V}_{\mathrm{T}} \\
(95 \% \mathrm{CI}), \mathrm{L}\end{array}$ & $\begin{array}{c}\text { PIP, } \mathrm{cm} \\
\mathrm{H}_{2} \mathrm{O}\end{array}$ & $\begin{array}{c}\text { PEEP, } \mathrm{cm} \\
\mathrm{H}_{2} \mathrm{O}\end{array}$ & $\begin{array}{l}\text { Mean } \mathrm{V}_{\mathrm{T}} \\
(95 \% \mathrm{CI}), \mathrm{L}\end{array}$ \\
\hline 2 & 20 & 5 & $0.888(0.882-0.894)$ & 8 & 5 & $0.082(0.080-0.085)$ \\
\hline 3 & 20 & 5 & $0.836(0.829-0.843)$ & 10 & 5 & $0.223(0.219-0.227)$ \\
\hline 4 & 19 & 5 & $0.834(0.824-0.843)$ & 12 & 5 & $0.353(0.351-0.356)$ \\
\hline 5 & 19 & 5 & $0.811(0.809-0.813)$ & 14 & 5 & $0.456(0.448-0.464)$ \\
\hline 6 & 18 & 5 & $0.788(0.782-0.793)$ & 15 & 5 & $0.546(0.543-0.548)$ \\
\hline 7 & 18 & 5 & $0.793(0.789-0.797)$ & 16 & 5 & $0.600(0.592-0.608)$ \\
\hline None & 18 & 5 & $0.764(0.763-0.766)$ & 18 & 5 & $0.716(0.714-0.718)$ \\
\hline \multicolumn{7}{|c|}{ Variable test-lung compliance with higher ventilator pressures } \\
\hline Compliance, $\mathrm{L} / \mathrm{cm} \mathrm{H}_{2} \mathrm{O}$ & \multicolumn{3}{|c|}{0.029} & \multicolumn{3}{|c|}{0.062} \\
\hline Resistor size, $\mathrm{mm}$ & $\begin{array}{c}\mathrm{PIP}, \mathrm{cm} \\
\mathrm{H}_{2} \mathrm{O}\end{array}$ & $\begin{array}{c}\text { PEEP, cm } \\
\mathrm{H}_{2} \mathrm{O}\end{array}$ & $\begin{array}{l}\text { Mean } \mathrm{V}_{\mathrm{T}} \\
(95 \% \mathrm{CI}), \mathrm{L}\end{array}$ & $\begin{array}{c}\text { PIP, } \mathrm{cm} \\
\mathrm{H}_{2} \mathrm{O}\end{array}$ & $\begin{array}{l}\text { PEEP, cm } \\
\qquad \mathrm{H}_{2} \mathrm{O}\end{array}$ & $\begin{array}{l}\text { Mean } \mathrm{V}_{\mathrm{T}} \\
(95 \% \mathrm{CI}), \mathrm{L}\end{array}$ \\
\hline 2 & 28 & 7 & $0.578(0.575-0.581)$ & 10 & 7 & $0.110(0.107-0.113)$ \\
\hline 3 & 27 & 7 & $0.526(0.517-0.536)$ & 12 & 7 & $0.290(0.286-0.294)$ \\
\hline 4 & 26 & 7 & $0.516(0.513-0.518)$ & 15 & 7 & $0.424(0.420-0.427)$ \\
\hline 5 & 25 & 7 & $0.512(0.511-0.513)$ & 17 & 7 & $0.542(0.537-0.548)$ \\
\hline 6 & 25 & 7 & $0.505(0.503-0.507)$ & 18 & 7 & $0.654(0.650-0.658)$ \\
\hline 7 & 26 & 7 & $0.555(0.552-0.558)$ & 20 & 7 & $0.773(0.770-0.776)$ \\
\hline None & 26 & 7 & $0.544(0.542-0.545)$ & 23 & 7 & $0.949(0.946-0.953)$ \\
\hline \multicolumn{7}{|c|}{ Variable test-lung compliance with lower ventilator pressures } \\
\hline Compliance, $\mathrm{L} / \mathrm{cm} \mathrm{H}_{2} \mathrm{O}$ & \multicolumn{3}{|c|}{0.030} & \multicolumn{3}{|c|}{0.062} \\
\hline Resistor size, $\mathrm{mm}$ & $\begin{array}{c}\mathrm{PIP}, \mathrm{cm} \\
\mathrm{H}_{2} \mathrm{O}\end{array}$ & $\begin{array}{c}\text { PEEP, } \mathrm{cm} \\
\mathrm{H}_{2} \mathrm{O}\end{array}$ & $\begin{array}{l}\text { Mean } V_{T} \\
(95 \% \text { CI), L }\end{array}$ & $\begin{array}{c}\text { PIP, } \mathrm{cm} \\
\mathrm{H}_{2} \mathrm{O}\end{array}$ & $\begin{array}{c}\text { PEEP, } \mathrm{cm} \\
\mathrm{H}_{2} \mathrm{O}\end{array}$ & $\begin{array}{l}\text { Mean } \mathrm{V}_{\mathrm{T}} \\
(95 \% \mathrm{CI}), \mathrm{L}\end{array}$ \\
\hline 2 & 21 & 5 & $0.403(0.391-0.414)$ & 8 & 5 & $0.091(0.090-0.093)$ \\
\hline 3 & 20 & 5 & $0.382(0.381-0.383)$ & 10 & 5 & $0.221(0.217-0.224)$ \\
\hline 4 & 19 & 5 & $0.386(0.385-0.387)$ & 12 & 5 & $0.325(0.322-0.328)$ \\
\hline 5 & 19 & 5 & $0.388(0.388-0.389)$ & 14 & 5 & $0.437(0.435-0.439)$ \\
\hline 6 & 19 & 5 & $0.406(0.404-0.408)$ & 15 & 5 & $0.536(0.532-0.540)$ \\
\hline 7 & 19 & 5 & $0.379(0.377-0.381)$ & 16 & 5 & $0.598(0.594-0.601)$ \\
\hline None & 19 & 5 & $0.385(0.384-0.386)$ & 18 & 5 & $0.707(0.703-0.711)$ \\
\hline \multicolumn{7}{|c|}{$\begin{array}{l}P<.001 \text { for all confidence intervals. } \\
P I P=\text { peak inspiratory pressure } \\
V_{\mathrm{T}}=\text { tidal volume }\end{array}$} \\
\hline
\end{tabular}

to the control lung increased to $28 \mathrm{~cm} \mathrm{H}_{2} \mathrm{O}$, while the measured PIP delivered to the control lung without any resistors in place was $24 \mathrm{~cm} \mathrm{H}_{2} \mathrm{O}$. Of note, there was effectively no change in the PEEP during the PIP titrations trials (Table 1).
PEEP was also reliably and incrementally titrated with the addition of a manual PEEP valve via LTV 900 expiratory tubing. With identical compliance and higher pressure settings, PEEP delivered to the experimental lung was adjustable from 7 to $27 \mathrm{~cm} \mathrm{H}_{2} \mathrm{O}$ and PEEP delivered to the 
Table 2. Titration of PEEP With the Addition of a Manual PEEP Valve

\begin{tabular}{|c|c|c|c|c|c|c|}
\hline & \multicolumn{3}{|c|}{ Control Lung } & \multicolumn{3}{|c|}{ Experimental Lung } \\
\hline & & & & & & Identical test-lung compliance with higher ventilator pressures \\
\hline Compliance, $\mathrm{L} / \mathrm{cm} \mathrm{H}_{2} \mathrm{O}$ & \multicolumn{3}{|c|}{0.060} & \multicolumn{3}{|c|}{0.061} \\
\hline PEEP valve addition to test lung $\mathrm{B}, \mathrm{cm} / \mathrm{H}_{2} \mathrm{O}$ & $\begin{array}{c}\mathrm{PIP}, \mathrm{cm} \\
\mathrm{H}_{2} \mathrm{O}\end{array}$ & $\begin{array}{c}\text { PEEP, cm } \\
\qquad \mathrm{H}_{2} \mathrm{O}\end{array}$ & $\begin{array}{l}\text { Mean } \mathrm{V}_{\mathrm{T}} \\
(95 \% \mathrm{CI}), \mathrm{L}\end{array}$ & $\begin{array}{c}\mathrm{PIP}, \mathrm{cm} \\
\mathrm{H}_{2} \mathrm{O}\end{array}$ & $\begin{array}{c}\text { PEEP, cm } \\
\qquad \mathrm{H}_{2} \mathrm{O}\end{array}$ & $\begin{array}{l}\text { Mean } \mathrm{V}_{\mathrm{T}} \\
(95 \% \mathrm{CI}), \mathrm{L}\end{array}$ \\
\hline 0 & 24 & 7 & $1.021(1.011-1.032)$ & 24 & 7 & $0.880(0.878-0.882)$ \\
\hline 5 & 25 & 7 & $1.067(1.065-1.069)$ & 26 & 11 & $0.765(0.758-0.772)$ \\
\hline 10 & 26 & 7 & $1.132(1.124-1.141)$ & 29 & 18 & $0.582(0.577-0.587)$ \\
\hline 15 & 27 & 7 & $1.162(1.158-1.166)$ & 30 & 21 & $0.485(0.481-0.489)$ \\
\hline 20 & 27 & 7 & $1.213(1.208-1.218)$ & 33 & 27 & $0.316(0.309-0.324)$ \\
\hline \multicolumn{7}{|c|}{ Identical test-lung compliance with lower ventilator pressures } \\
\hline Compliance, $\mathrm{L} / \mathrm{cm} \mathrm{H}_{2} \mathrm{O}$ & \multicolumn{3}{|c|}{0.059} & \multicolumn{3}{|c|}{0.060} \\
\hline $\mathrm{PEEP}$ valve addition to test lung $\mathrm{B}, \mathrm{cm} / \mathrm{H}_{2} \mathrm{O}$ & $\begin{array}{r}\text { PIP, cm } \\
\mathrm{H}_{2} \mathrm{O}\end{array}$ & $\begin{array}{c}\text { PEEP, } \mathrm{cm} \\
\mathrm{H}_{2} \mathrm{O}\end{array}$ & $\begin{array}{l}\text { Mean } V_{T} \\
(95 \% \text { CI }), L\end{array}$ & $\begin{array}{c}\text { PIP, cm } \\
\mathrm{H}_{2} \mathrm{O}\end{array}$ & $\begin{array}{c}\text { PEEP, } \mathrm{cm} \\
\mathrm{H}_{2} \mathrm{O}\end{array}$ & $\begin{array}{l}\text { Mean } \mathrm{V}_{\mathrm{T}} \\
(95 \% \mathrm{CI}), \mathrm{L}\end{array}$ \\
\hline 0 & 18 & 5 & $0.780(0.775-0.785)$ & 17 & 5 & $0.680(0.673-0.687)$ \\
\hline 5 & 19 & 5 & $0.821(0.820-0.822)$ & 19 & 10 & $0.469(0.464-0.474)$ \\
\hline 10 & 20 & 5 & $0.869(0.865-0.872)$ & 22 & 16 & $0.286(0.285-0.288)$ \\
\hline 15 & 20 & 5 & $0.897(0.891-0.903)$ & 23 & 19 & $0.169(0.167-0.171)$ \\
\hline 20 & 20 & 5 & $0.918(0.914-0.921)$ & NA & NA & NA \\
\hline \multicolumn{7}{|c|}{ Variable test-lung compliance with higher ventilator pressures } \\
\hline Compliance, $\mathrm{L} / \mathrm{cm} \mathrm{H}_{2} \mathrm{O}$ & \multicolumn{3}{|c|}{0.060} & \multicolumn{3}{|c|}{0.031} \\
\hline PEEP valve addition to test lung $\mathrm{B}, \mathrm{cm} / \mathrm{H}_{2} \mathrm{O}$ & $\begin{array}{r}\text { PIP, cm } \\
\mathrm{H}_{2} \mathrm{O}\end{array}$ & $\begin{array}{c}\text { PEEP, } \mathrm{cm} \\
\mathrm{H}_{2} \mathrm{O}\end{array}$ & $\begin{array}{l}\text { Mean } \mathrm{V}_{\mathrm{T}} \\
(95 \% \mathrm{CI}), \mathrm{L}\end{array}$ & $\begin{array}{c}\text { PIP, } \mathrm{cm} \\
\mathrm{H}_{2} \mathrm{O}\end{array}$ & $\begin{array}{c}\text { PEEP, cm } \\
\qquad \mathrm{H}_{2} \mathrm{O}\end{array}$ & $\begin{array}{l}\text { Mean } \mathrm{V}_{\mathrm{T}} \\
(95 \% \mathrm{CI}), \mathrm{L}\end{array}$ \\
\hline 0 & 27 & 7 & $1.122(1.121-1.123)$ & 31 & 7 & $0.690(0.687-0.692)$ \\
\hline 5 & 27 & 7 & $1.132(1.126-1.138)$ & 32 & 10 & $0.607(0.601-0.614)$ \\
\hline 10 & 27 & 7 & $1.184(1.179-1.189)$ & 34 & 16 & $0.459(0.456-0.462)$ \\
\hline 15 & 28 & 7 & $1.200(1.199-1.202)$ & 35 & 20 & $0.363(0.359-0.366)$ \\
\hline 20 & 28 & 7 & $1.229(1.222-1.235)$ & 36 & 25 & $0.255(0.254-0.257)$ \\
\hline \multicolumn{7}{|c|}{ Variable test-lung compliance with lower ventilator pressures } \\
\hline Compliance, $\mathrm{L} / \mathrm{cm} \mathrm{H}_{2} \mathrm{O}$ & \multicolumn{3}{|c|}{0.059} & \multicolumn{3}{|c|}{0.031} \\
\hline PEEP valve addition to test lung $\mathrm{B}, \mathrm{cm} / \mathrm{H}_{2} \mathrm{O}$ & $\begin{array}{r}\text { PIP, cm } \\
\mathrm{H}_{2} \mathrm{O}\end{array}$ & $\begin{array}{c}\text { PEEP, } \mathrm{cm} \\
\mathrm{H}_{2} \mathrm{O}\end{array}$ & $\begin{array}{l}\text { Mean } \mathrm{V}_{\mathrm{T}} \\
(95 \% \mathrm{CI}), \mathrm{L}\end{array}$ & $\begin{array}{c}\text { PIP, cm } \\
\mathrm{H}_{2} \mathrm{O}\end{array}$ & $\begin{array}{c}\text { PEEP, } \mathrm{cm} \\
\mathrm{H}_{2} \mathrm{O}\end{array}$ & $\begin{array}{l}\text { Mean } \mathrm{V}_{\mathrm{T}} \\
(95 \% \mathrm{CI}), \mathrm{L}\end{array}$ \\
\hline 0 & 20 & 5 & $0.875(0.871-0.879)$ & 22 & 5 & $0.454(0.452-0.456)$ \\
\hline 5 & 20 & 5 & $0.877(0.875-0.879)$ & 23 & 8 & $0.367(0.365-0.369)$ \\
\hline 10 & 20 & 5 & $0.895(0.892-0.897)$ & 24 & 15 & $0.210(0.208-0.213)$ \\
\hline 15 & 20 & 5 & $0.911(0.909-0.912)$ & 25 & 19 & $0.118(0.105-0.131)$ \\
\hline 20 & 20 & 5 & $0.914(0.912-0.916)$ & NA & NA & NA \\
\hline \multicolumn{7}{|c|}{$\begin{array}{l}P<.001 \text { for all confidence intervals. } \\
P I P=\text { peak inspiratory pressure } \\
V_{\mathrm{T}}=\text { tidal volume } \\
\mathrm{NA}=\text { not applicable (ie, the parameters were unmeasurable at this setting) }\end{array}$} \\
\hline
\end{tabular}

control lung remained stable at $7 \mathrm{~cm} \mathrm{H}_{2} \mathrm{O}$. With identical compliance and lower pressure settings, PEEP delivered to the experimental lung was adjustable from 5 to $19 \mathrm{~cm} \mathrm{H}_{2} \mathrm{O}$ and PEEP delivered to the control lung remained constant at $5 \mathrm{~cm} \mathrm{H}_{2} \mathrm{O}$. With differential compliance and higher pressure settings, PEEP delivered to the experimental lung was adjustable from 7 to $25 \mathrm{~cm} \mathrm{H}_{2} \mathrm{O}$ and PEEP delivered to the control lung remained stable at $7 \mathrm{~cm} \mathrm{H}_{2} \mathrm{O}$. With differential compliance and lower pressure settings, PEEP delivered to the experimental lung was adjustable from 5 to $19 \mathrm{~cm} \mathrm{H}_{2} \mathrm{O}$ and PEEP delivered to the control lung remained constant at $5 \mathrm{~cm} \mathrm{H}_{2} \mathrm{O}$ (Table 2).
As PEEP delivered to the experimental lung was increased, the PIP delivered to the experimental lung also increased gradually. However, the driving pressures and tidal volumes decreased at very high PEEP levels $(>15-20$ $\mathrm{cm}_{2} \mathrm{O}$ ). Furthermore, as PEEP delivered to the experimental lung was increased, the PIP delivered to the control lung increased. With identical compliance and higher pressure settings, the measured PIP increased from 24 to $27 \mathrm{~cm}$ $\mathrm{H}_{2} \mathrm{O}$.

Lastly, $\mathrm{F}_{\mathrm{IO}_{2}}$ was titrated by adding a one-way valve and T-piece with an oxygen source and tubing to the inspiratory circuit of the experimental lung. With identical compliance, 
Table 3. Titration of $\mathrm{F}_{\mathrm{IO}_{2}}$ by Addition of Oxygen Flow

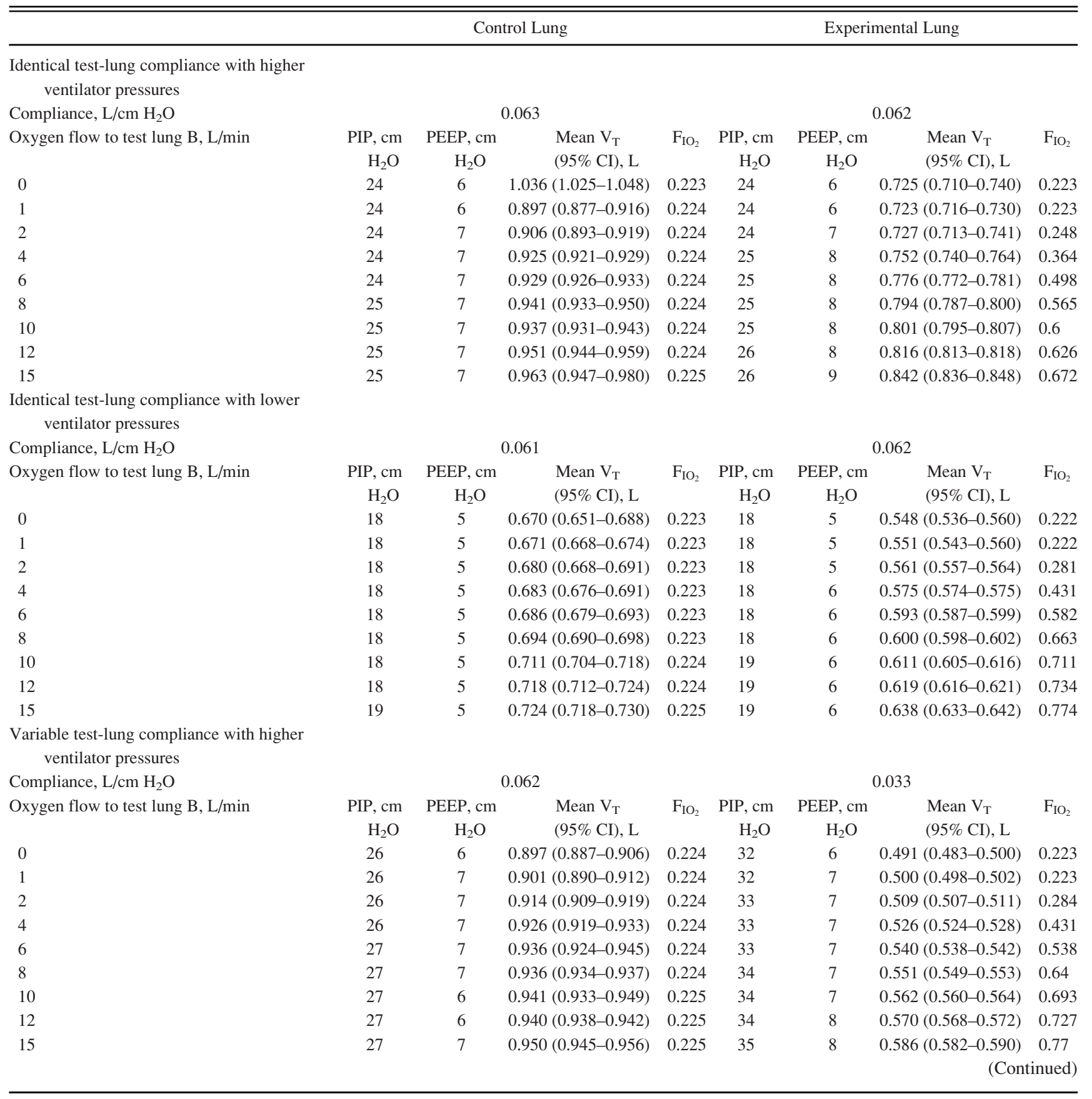

higher pressure settings, and the ventilator $\mathrm{F}_{\mathrm{IO}_{2}}$ set at 0.21 the $\mathrm{F}_{\mathrm{IO}_{2}}$ delivered to the experimental lung was adjustable from $22.3 \%$ to $67.2 \%$, while the $\mathrm{F}_{\mathrm{IO}_{2}}$ delivered to the control lung remained relatively stable between $22.3 \%$ and $22.5 \%$. Of note, when ventilating test lungs at lower pressure settings, higher delivered $\mathrm{F}_{\mathrm{IO}_{2}}$ was achieved. This difference was exaggerated when the compliance of the experimental lung was decreased, achieving $\mathrm{F}_{\mathrm{IO}_{2}}$ as high as 90.6\% (Table 3).

\section{Discussion}

The era of COVID-19 has exposed limitations of the global health care system, including paucities of ventilators during surges of respiratory illness. ${ }^{6}$ Inadequate resources may have led to preventable deaths. ${ }^{10}$ Practicing medicine in resource-limited settings necessitates ingenuity. Novel means to provide respiratory support have been developed, including dual-patient, single-ventilator protocols. ${ }^{9,11-}$ 
Shared Ventilation With a Portable Ventilator

Table 3. Continued

\begin{tabular}{|c|c|c|c|c|c|c|c|c|}
\hline \multicolumn{9}{|c|}{ Experimental Lung } \\
\hline \multicolumn{9}{|c|}{$\begin{array}{l}\text { Variable test-lung compliance with lower } \\
\text { ventilator pressures }\end{array}$} \\
\hline \multirow{2}{*}{$\begin{array}{l}\text { Compliance, } \mathrm{L} / \mathrm{cm}_{2} \mathrm{O} \\
\text { Oxygen flow to test lung } \mathrm{B}, \mathrm{L} / \mathrm{min}\end{array}$} & \multicolumn{4}{|c|}{0.062} & \multicolumn{4}{|c|}{0.033} \\
\hline & $\begin{array}{c}\mathrm{PIP}, \mathrm{cm} \\
\mathrm{H}_{2} \mathrm{O}\end{array}$ & $\begin{array}{c}\text { PEEP, cm } \\
\quad \mathrm{H}_{2} \mathrm{O}\end{array}$ & $\begin{array}{l}\text { Mean } \mathrm{V}_{\mathrm{T}} \\
(95 \% \mathrm{CI}), \mathrm{L}\end{array}$ & $\mathrm{F}_{\mathrm{IO}_{2}}$ & $\begin{array}{c}\mathrm{PIP}, \mathrm{cm} \\
\mathrm{H}_{2} \mathrm{O}\end{array}$ & $\begin{array}{c}\text { PEEP, cm } \\
\quad \mathrm{H}_{2} \mathrm{O}\end{array}$ & $\begin{array}{l}\text { Mean } \mathrm{V}_{\mathrm{T}} \\
(95 \% \mathrm{CI}), \mathrm{L}\end{array}$ & $\mathrm{F}_{\mathrm{IO}_{2}}$ \\
\hline 0 & 20 & 5 & $0.681(0.675-0.687)$ & 0.222 & 23 & 5 & $0.324(0.322-0.326)$ & 0.223 \\
\hline 1 & 20 & 5 & $0.695(0.698-0.700)$ & 0.222 & 23 & 5 & $0.329(0.326-0.332)$ & 0.228 \\
\hline 2 & 20 & 5 & $0.705(0.702-0.707)$ & 0.223 & 23 & 5 & $0.340(0.339-0.341)$ & 0.325 \\
\hline 4 & 20 & 5 & $0.713(0.710-0.716)$ & 0.223 & 23 & 5 & $0.362(0.360-0.364)$ & 0.535 \\
\hline 6 & 20 & 5 & $0.712(0.708-0.717)$ & 0.223 & 23 & 5 & $0.381(0.380-0.381)$ & 0.687 \\
\hline 8 & 20 & 5 & $0.720(0.718-0.722)$ & 0.225 & 24 & 5 & $0.395(0.393-0.398)$ & 0.8 \\
\hline 10 & 20 & 5 & $0.713(0.710-0.716)$ & 0.225 & 24 & 5 & $0.407(0.405-0.409)$ & 0.868 \\
\hline 12 & 20 & 5 & $0.719(0.716-0.722)$ & 0.225 & 25 & 5 & $0.418(0.417-0.418)$ & 0.882 \\
\hline 15 & 20 & 5 & $0.723(0.716-0.730)$ & 0.228 & 26 & 6 & $0.435(0.431-0.438)$ & 0.906 \\
\hline $\begin{array}{l}P<.001 \text { for all confidence intervals. } \\
P I P=\text { peak inspiratory pressure } \\
\mathrm{V}_{\mathrm{T}}=\text { tidal volume }\end{array}$ & & & & & & & & \\
\hline
\end{tabular}

${ }^{13}$ Concerns have been raised regarding the ethics of this method, as it deviates from standard of care. However, withholding ventilators from patients in need may be more harmful. ${ }^{14,15}$ Though the incidence of ARDS from COVID19 appears to be diminishing in some regions, other regions are seeing a steady increase in cases. ${ }^{16,17}$ By innovating a means to individually titrate PIP, PEEP, and $\mathrm{F}_{\mathrm{IO}_{2}}$ in a dualpatient, single-ventilator circuit, we hope to allow providers to better care for their patients.

\section{PIP}

Titration of PIP to an individual test lung was simple, reliable, and incrementally and linearly adjustable. The PIP delivered from the ventilator to a single test lung could be diminished by $>50 \%$ with the addition of a resistor. Thus, the delivered tidal volume could be adjusted over a large range when utilizing a dual-patient, single-ventilator circuit. Notably, when applied to humans, the exact delivered PIP would depend on several variables, including the compliance of each patient's lungs and the diameter of a specific resistor. However, this could be addressed by adjusting sequentially sized resistors and monitoring the PIP and tidal volumes delivered.

Several interactions were noted during the PIP titrations. First, prior to the addition of any resistors, the PIP delivered to each test lung was measured to be lower than the PIP set at the ventilator. Second, as PIP delivered to the experimental lung was diminished by the addition of resistors, the PIP delivered to the control lung increased slightly. Third, in test lungs with differential compliance, the PIP delivered to the test lung with higher compliance was larger even without the addition of resistors.
Some of these interactions may be explained by the following. As the resistance increases in one test lung, the PIP delivered to that test lung decreases while the PIP delivered to the test lung with lower resistance increases. Air flow follows the path of least resistance, delivering higher pressures and volumes to the lung with the lowest resistance. Another potential contributor is that the ventilator will increase its output to achieve the set PIP at the level of the airway flow sensor and cannot titrate the individual pressures at the level of each test lung.

Of note, the changes observed in the control lung were not clinically important, with an observed increase in PIP of about 1-2 $\mathrm{cm} \mathrm{H}_{2} \mathrm{O}$. In human patients, tidal volume and PEEP delivery to the circuit of one patient may not be significantly affected by the addition of resistors to the inspiratory circuit of a second patient connected to the same ventilator. The authors highly recommend close monitoring of delivered tidal volumes and pressures if this intervention is utilized.

\section{PEEP}

The titration of PEEP delivered to an individual test lung was reliably, incrementally, and linearly adjustable. The PEEP could be increased well above $20 \mathrm{~cm} \mathrm{H}_{2} \mathrm{O}$ in the experimental lung. There were several notable interactions during the PEEP titrations. Similar to the findings during the PIP titrations, the PIP delivered to the control lung increased slightly as the PEEP of the circuit to the experimental lung was increased. Second, as the PEEP in the experimental lung was increased, the driving pressure decreased. When the PEEP reached supra-physiologic levels (ie, $>15 \mathrm{~cm} \mathrm{H}_{2} \mathrm{O}$ ), the tidal volumes decreased significantly due to loss of driving pressure. 


\section{Shared Ventilation With a Portable Ventilator}

We believe that this second finding may be explained by diversion of air flow down the path of least resistance. As the PEEP was increased to supra-physiologic levels, the flow of air was likely diverted to the control lung. Although high PEEPs (ie, $>15-20 \mathrm{~cm} \mathrm{H}_{2} \mathrm{O}$ ) will not be frequently clinically applicable, extreme caution with this application is advised. More modest PEEP titrations could be considered in human patients with close monitoring.

$\mathrm{F}_{\mathrm{IO}_{2}}$

The delivered $\mathrm{F}_{\mathrm{IO}_{2}}$ for the experimental lung was readily increased without any significant changes in the $\mathrm{F}_{\mathrm{IO}_{2}}$ received by the control lung. Using this method, the $\mathrm{F}_{\mathrm{IO}_{2}}$ received by the experimental lung could be increased as high as $90.6 \%$ while the $\mathrm{F}_{\mathrm{IO}_{2}}$ delivered to the control lung remained stable at $\sim 22.3 \%$. This implies that a single patient can be adequately oxygenated with a dual-patient, single-ventilator circuit when the other patient does not require additional $\mathrm{F}_{\mathrm{IO}_{2}}$.

There were several notable interactions during the oxygen titration trials. First, as oxygen flow to the experimental lung was increased, the PIP and PEEP delivered to the experimental lung also increased. This can be explained by the additional air flow in that circuit. Second, as the oxygen flow to the experimental lung was increased, the PIP delivered to the control lung also increased slightly, perhaps due to increased back pressure in the experimental lung's circuit shunting ventilator air flow to the control lung. Third, a higher $\mathrm{F}_{\mathrm{IO}_{2}}$ was achieved when ventilating the experimental lung with low pressure settings. When the minute ventilation is decreased with fixed oxygen delivery, the $\mathrm{F}_{\mathrm{IO}_{2}}$ will increase.

Thus PIP, PEEP, and $\mathrm{F}_{\mathrm{IO}_{2}}$ were adjustable using these methods. Some interactions were noted, underscoring the need for extreme caution and close monitoring of patients ventilated via a dual-patient, single-ventilator circuit. We believe that these interactions may be addressed using the discussed methods to titrate settings.

\section{Limitations}

There were several limitations of this study. First, these methods were only trialed in test lungs. To our knowledge, similar strategies have not been tested in humans. However, test lungs are predictors of human lung physiology. These findings have the potential to translate well to animal or human models. Second, we only applied our intervention using the LTV 1200 ventilator and LTV 900 expiratory circuit tubing. These supplies may not be available at every institution. Also, we did not conduct a complete safety assessment. The addition of one-way valves may lead to detrimentally variable pressures. We tried to mitigate this risk with the addition of a manual manometer to each circuit with a pop-off valve that would allow for temporization of critical pressures that exceed $40 \mathrm{~cm} \mathrm{H}_{2} \mathrm{O}$. We did not encounter unsafely high delivered pressures in our study. It would be wise to consider circumspective safety mechanisms in future applications.

In addition, with this current prototype model, it is difficult to quickly adjust the resistors and thus the delivered PIP. The use of an adjustable PIP resistor would be beneficial to facilitate rapid and reliable titration. Also, we did not include important adaptors such as anti-asphyxia valves or viral filters in our prototype split-ventilator model. These should be included for safety purposes, and future studies in parameter titration in split ventilation should examine the system for unintended effects of adding more adaptors to the circuit.

Furthermore, while the compliance was known during each experimental phase, airway resistance was not specifically measured. Finally, although sedation and muscle relaxation are recommended when using a dual-patient ventilation protocol, we were unable to assess the presence and effects of ventilator asynchrony if muscle relaxation were inadequate. These factors should be considered when the techniques described herein are implemented in vivo.

\section{Conclusions}

Titrating ventilator settings is essential for patients with respiratory pathology. Ventilating patients with different lung compliances on a dual-patient ventilation protocol without a means to titrate individual pressures or delivered oxygen is dangerous. Furthermore, certain respiratory pathologies necessitate specific ventilation strategies.

We recognize that the utilization of dual-patient, singleventilator protocols is potentially harmful and has yet to be shown to improve survival. Our hope is that the introduction of these concepts may create a framework toward making these protocols safer. We do not condone the use of these protocols. We believe they should only be used as a last option when safer and well-validated types of respiratory support are unavailable.

Future directions for this research include close assessment of factors that affect the pressure interactions when adjusting variables in the dual-patient, single-ventilator circuit. This may include a comparison of ventilatory curves between the 2 test lungs in the different trials evaluated. Another potential research avenue is applying these methods to animal models, which could confirm the safety and support the proof of concept. Moreover, it would be useful to apply these ideas to other commonly used ventilators across hospitals. Additionally, there could be interest in performing multiple-patient ventilation of $>2$ patients with variable parameters when using a single ventilator. Lastly, in each phase of the experiment, variables were documented with only a single change made to the ventilator circuit (ie, either a resistor to adjust the PIP, a manual PEEP 


\section{Shared Ventilation With a Portable Ventilator}

valve, or an oxygen tubing adapter). Future studies could examine the interactions between PIP, PEEP, and $\mathrm{F}_{\mathrm{IO}_{2}}$ if all 3 elements were utilized simultaneously.

\section{ACKNOWLEDGMENT}

We thank Mark R Zonfrillo MD MSCE, of Hasbro Children's Hospital, Warren Alpert Medical School at Brown University, for his review of this manuscript.

\section{REFERENCES}

1. Branson RD, Blakeman TC, Robinson BR, Johannigman JA. Use of a single ventilator to support 4 patients: laboratory evaluation of a limited concept. Respir Care 2012;57(3):399-403.

2. Neyman G, Irvin CB. A single ventilator for multiple simulated patients to meet disaster surge. Acad Emerg Med 2006;13(11):12461249.

3. Paladino L, Silverberg M, Charchaflieh JG, Eason JK, Wright BJ, Palamidessi $\mathrm{N}$, et al. Increasing ventilator surge capacity in disasters: ventilation of four adult-human-sized sheep on a single ventilator with a modified circuit. Resuscitation 2008;77(1):121-126.

4. Smith R, Brown J. Simultaneous ventilation of two healthy subjects with a single ventilator. Resuscitation 2009;80(9): 1087.

5. New York approves ventilator splitting, allowing hospitals to treat two patients with one machine. ABC News. March 26, 2020. Available at: https://abcnews.go.com/US/york-approves-ventilator-splitting-allowinghospitals-treat-patients/story?id=69816167. Accessed April 4, 2020.

6. 'The other option is death': New York starts sharing of ventilators. New York Times. Mar 26, 2020. Available at: https://www.nytimes. com/2020/03/26/health/coronavirus-ventilator-sharing.html. Accessed April 4, 2020.

7. Greater New York Hospital Association. Ventilator sharing protocol: dual-patient ventilation with a single mechanical ventilator for use during critical ventilator shortages. Available at: https://www.gnyha.org/ news/working-protocol-for-supporting-two-patients-with-a-singleventilator. Accessed April 4, 2020.
8. Society of Critical Care Medicine. Consensus Statement on Multiple Patients Per Ventilator. March 26, 2020. Available at: https://www. sccm.org/Disaster/Joint-Statement-on-Multiple-Patients-Per-Ventilato. Accessed April 4, 2020.

9. Clarke A, Stephens A, Liao S, Byrne T, Gregory S. Coping with COVID-19: ventilator splitting with differential driving pressures using standard hospital equipment. Anaesthesia 2020;75(7):872-880.

10. Italian priest with coronavirus who gave his ventilator to younger patient has reportedly died. USA Today. March 24, 2020. Available at: https://www.usatoday.com/story/news/world/2020/03/24/covid-19italian-priest-who-donated-his-ventilator-has-reportedly-died/ 2906351001. Accessed April 4, 2020.

11. Pearson SD, Hall JB, Parker WF. Two for one with split-or co-ventilation at the peak of the Covid-19 tsunami: is there any role for communal care when the resources for personalised medicine are exhausted? Thorax 2020;75(6):444-445.

12. Srinivasan SS, Ramadi KB, Vicario F, Gwynne D, Hayward A, Lagier $\mathrm{D}$, et al. A rapidly deployable individualized system for augmenting ventilator capacity. Sci Transl Med 2020;12(549):eabb9401.

13. Tonetti T, Zanella A, Pizzilli G, Babcock CI, Venturi S, Nava S, et al. One ventilator for two patients: feasibility and considerations of a last resort solution in case of equipment shortage. Thorax 2020;75(6):517519.

14. Cohen IG, Crespo AM, White DB. Potential legal liability for withdrawing or withholding ventilators during COVID-19: assessing the risks and identifying needed reforms. JAMA 2020;323(19):19011902.

15. White DB, Lo B. A framework for rationing ventilators and critical care beds during the COVID-19 pandemic. JAMA 2020;323(18):1773-1774.

16. As coronavirus rebounds, more patients are being hospitalized and capacity is stretched. The Washington Post. July 2, 2020. Available at: https://www.washingtonpost.com/politics/as-coronavirus-reboundsmore-patients-are-being-hospitalized-thats-a-bad-sign/2020/07/02/ 62f60720-bc4f-11ea-80b9-40ece9a701dc_story.html. Accessed July 10, 2020.

17. Covid hospitalizations surge as pandemic enters alarming new phase in U.S. NBC News. Nov 3, 2020. Available at: https://www.nbcnews.com/ health/health-news/covid-hospitalizations-surge-pandemic-entersalarming-new-phase-u-s-n1246068. Accessed November 5, 2020. 